\title{
APRENDIZAGEM ESCOLAR ENTRE INDÍGENAS KAINGANG NO PARANÁ: questões sobre língua, alfabetização e letramento
}

\author{
SCHOOL LEARNING AMONG THE KAINGANG \\ INDIGENOUS PEOPLE IN THE STATE OF PARANÁ: \\ language, literacy and language learning issues
}

Rosângela Célia Faustino*

\begin{abstract}
Resumo
O presente texto tematiza a alfabetização, o letramento e a relação desses com a língua materna de indígenas Kaingang no estado do Paraná. Baseado em dados coletados em pesquisa de campo, bibliográfica e documental (2007-2010), discute as políticas públicas de inclusão social e a atual política de educação escolar indígena elaborada nos anos de 1990 pelo Ministério da Educação - MEC. Salienta como essa pode contribuir com o acesso ao conhecimento científico entre grupos étnicos, ampliando as possibilidades de letramento, cidadania e autonomia indígena.
\end{abstract}

Palavras-chave: Alfabetização. Letramento. Índios Kaingang.

\begin{abstract}
The present paper studies the issues of literacy and language learning in relation to the mother tongue of the Kaingang indigenous people in the state of Paraná. Based on data collected in field research, literature and documents (20072010), it discusses the public policies for social inclusion and the current policy of indigenous education developed in 1990 by the Ministry of Education - MEC. It also points out how this policy can foster the access to scientific knowledge among ethnic groups, increasing the chances of literacy, citizenship and indigenous autonomy.
\end{abstract}

Keywords: Literacy. Language Learning. Kaingang Indigenous People.

\section{Introdução}

Melhorar as condições das escolas nas comunidades indígenas atende a um direito humano fundamental, pois a educação sistematizada contribui para o desenvolvimento das funções psíquicas superiores - atenção, memória, imaginação, percepção, emoções, pensamento, linguagem oral e escrita dentre outras. (VIGOTSKY, 1987). Essas funções são essencialmente humanas, e têm o papel de organizar adequadamente a vida do indivíduo em seu meio sociocultural.

A linguagem, oral e escrita, é instrumento do pensamento humano por meio da qual nos apropriamos e transmitimos conceitos, ideias e experiências. Sendo os grupos indígenas portadores de culturas (línguas e tradições) diferenciadas, pensar a escola, a alfabetização e o letramento indígena requer estudos e investigações acerca do bilinguismo, de teorias e métodos de ensino e aprendizagem para que se possa ter uma melhor dimensão de como esse processo pode contribuir com a ampliação da cidadania dos diferentes grupos étnicos existentes no Brasil na atualidade.

A aprendizagem e o desenvolvimento nos seres humanos constituem-se como processos que se consolidam nas interações sociais do indivíduo com a história e a cultura de seu povo, com o conhecimento adquirido nas diferentes situações vividas, na resolução de problemas, nos hábitos, valores, crenças, comportamentos e linguagem cotidiana. Nesse sentido reconhecem-se as profundas implicações da introdução da escrita em culturas chamadas tradicionais.

Tendo em vista as modificações nas formas de vida dos grupos indígenas, processadas em ritmo vertiginoso a partir dos processos de ocupação de terras no Brasil, a inserção da instituição escolar entre esses grupos, no início, refutada, encontra-se aceita, e é reivindicada pela grande maioria das etnias.

As políticas públicas em curso no Paraná têm mobilizado a formação de professores indígenas magistério específico -, acesso ao Ensino Superior por meio de vagas suplementares, provimento de

\footnotetext{
*Professora do PPGE da Universidade Estadual de Maringá. E-mail: rofaustino@terra.com.br
} 
material de apoio pedagógico diferenciado, pesquisas e extensões universitárias.

Entre os Kaingang, a escola não foi incorporada pela cultura nativa, mas ocupa um lugar importante nas aldeias. Se a instituição educativa estiver organizada de acordo com os princípios da qualidade, amplia as possibilidades de aprendizagem e de desenvolvimento na medida em que disponibiliza outros elementos de interação, além daqueles provenientes da própria cultura, porém deve ser pensada sem que se perca de vista as especificidades e interesses étnicos.

A discussão aqui apresentada provém da reflexão a partir de uma experiência que envolve pesquisa, extensão e intervenção pedagógica, realizada ao longo dos anos de 2007 e 2010 por uma equipe do Programa Interdisciplinar de Estudos de Populações - Laboratório de Arqueologia, Etnologia e Etno-História da Universidade Estadual de Maringá. Esse Programa vem desenvolvendo projetos em diferentes Terras Indígenas no Paraná. A experiência aqui abordada, contou com financiamento do Programa Universidade Sem Fronteiras/ SETI - por meio da Secretaria de Estado da Ciência, Tecnologia e Ensino Superior do Paraná. A continuidade da mesma foi possível com apoio da CAPES/INEP/DEB, por meio do Programa Observatório da Educação Escolar Indígena.

\section{Aspectos históricos do processo de escola- rização Kaingang}

No Paraná existem atualmente três diferentes grupos étnicos - os Xetá, os Kaingang e os Guarani - totalizando cerca de 12 mil indígenas, sendo esses majoritariamente pertencentes aos grupos Kaingang e Guarani, uma vez que os Xetá encontram-se em processo de reorganização cultural devido à grande perda populacional que sofreram, ocasionada pelo violento processo de colonização do estado nos anos de 1950/1960. (SILVA, 1998).

Esses grupos vivem em 21 Terras Indígenas demarcadas e em outras seis em processo de demarcação, o que significa que estão em momento de expansão territorial e crescimento populacional. Linguisticamente, os Guarani e os Xetá pertencem ao Tronco Tupi (GABAS Jr., 2006) e os grupos Kaingang, pertencem ao Tronco Macro-Jê. (D'ANGELIS, 2007). Esses grupos étnicos são bastante diferentes entre si no modo de pensar, agir, compreender e explicar o mundo.

Após um longo processo histórico de perdas territoriais e populacionais aos indígenas no Paraná, e de forma geral no Brasil, estão sendo elaboradas diversas políticas públicas que visam ao seu conhecimento, reconhecimento e respeito pela diversidade cultural. Essas políticas, introduzidas no Brasil por meio da Constituição Federal de 1988 estão pautadas nos princípios do bilinguismo e da interculturalidade. (FAUSTINO, 2006).

A diversidade nem sempre foi valorizada. A legislação atual de inclusão e reconhecimento tem por intuito reverter uma situação criada no processo de colonização, durante o qual, em conluio com a exploração da mão de obra nativa e à mercantilização das terras ocupadas, as políticas se voltavam para a garantia da submissão, adaptação/incorporação indígena à sociedade majoritária. Foram usadas diferentes estratégias para esse fim, desde coerção, violência, cooptação até assimilação - para fazer os grupos indígenas abandonarem seus costumes, crenças e línguas -, levadas a cabo por sucessivos governos.

Nesse processo foi implementada uma série de medidas, englobando, inclusive, a instituição escolar para a "civilização" dos indígenas. Essa estratégia visava, basicamente, ao abandono da língua indígena, das terras e à adoção exclusiva da língua nacional, bem como à inserção no mercado de trabalho.

Em meados do século XVIII, o ministro Sebastião
José de Carvalho e Melo, futuro Marquês de Pom-
bal, elaborou uma série de medidas visando integrar
as populações indígenas da América à sociedade
colonial portuguesa. Estas medidas foram sistemati-
zadas no Diretório que se deve observar nas povo-
ações dos índios do Pará e do Maranhão enquanto
sua majestade não mandar o contrário, publicado
em 3 de maio de 1757 e transformado em lei por
meio do alvará de 17 de agosto de 1758 . O Diretório
tinha como objetivo principal a completa integração
dos índios à sociedade portuguesa buscando não
apenas o fim das discriminações sobre estes, mas
a extinção das diferenças entre índios e brancos.
Dessa forma, projetava um futuro no qual não seria
possível distinguir uns dos outros, seja em termos
físicos, por meio da miscigenação biológica, seja em
termos comportamentais, por intermédio de uma sé-
rie de dispositivos de homogeneização cultural [...]
A perspectiva de impor aos índios o uso da língua
portuguesa, tinha um objetivo bem claro neste perí-
odo: buscava transformá-los em vassalos iguais aos
demais colonos. (GARCIA, 2007 , p. 21 ).

A busca da assimilação não foi tranquila, havendo inúmeros relatos e documentos (MOTA, 1998) que demonstram a resistência e o enfrentamento dos indígenas às políticas governamentais. Do ponto de vista da educação, os grupos Kaingang se recusavam a mandar seus filhos para a escola e a abandonar suas tradições, resistindo à dominação linguística. Essa resistência evidencia-se principalmente pelo fato de que, decorridos vários séculos de políticas de integração, os Kaingang são falantes da língua materna, o kaingang, na grande maioria das Terras Indígenas no Paraná e esse grupo figura entre os que detêm o maior número de falantes no Brasil. 
Os primeiros projetos de educação formal aos indígenas, após a criação da FUNAI (Fundação Nacional do Índio), foram implementados na década de 1970 pelo SIL (Summer Institute of Linguistics). Essa agência religiosa/protestante norte-americana, em convênio com a FUNAI/MEC/USAID (FAUSTINO, 2006), catalogou e instituiu, para a língua kaingang, via escola, o código escrito. Para esse processo, a missionária alemã Úrsula Wiesemann utilizou a Teoria Tagmêmica desenvolvida por Kenneth Pike, baseando-se na descrição fonológica da língua falada (SILVA, 1996).

Para a consolidação do projeto, o SIL fundou, no início da década de 1970 , no município de Guarita (Rio Grande do Sul), a primeira escola para formação de professores bilíngues - a Escola Clara Camarão. Nessa, os indígenas eram alfabetizados para se tornarem monitores e auxiliares dos missionários que, em sala de aula, fariam a alfabetização das crianças indígenas. $O$ processo utilizado foi o denominado "bilinguismo de ponte" (FAUSTINO, 2006), configurado pelo uso da língua materna nas primeiras séries até se chegar ao domínio da escrita, do código e da transposição para a língua nacional. As análises desse processo (BARROS, 1993, 1994, 2004; LEITE, 1981) mostram que esse método subjuga a língua materna dos grupos minoritários, colocando-a em segundo plano ou até mesmo rejeitando-a, posteriormente contribuindo para que seja vista como uma língua menor, sem prestígio.

Como os fundamentos do projeto do SIL são religiosos, ocultados em ações linguístico-educativas, os materiais didáticos elaborados em kaingang, no decorrer de toda a década de 1970 até meados da década de 1990 são evangelhos, cartilhas, hinos e textos bíblicos utilizados tanto na Igreja como na escola. Não se encontram nas bibliotecas escolares adjacentes às escolas indígenas, materiais bilíngues com conteúdo científico. Considerando que o SIL agia em acordo com a FUNAl e outras instituições governamentais, não foram estimuladas outras produções não confessionais.

Embora a Escola Clara Camarão tenha formado turmas cujos monitores bilíngues - mesmo sem receber a devida certificação, pois o curso não foi reconhecido - atuam em diferentes Terras Indígenas, pouco se avançou em termos de alfabetização e de letramento indígena, pois estudos (FAUSTINO, 2006) evidenciam baixíssimo índice de pessoas letradas nas comunidades.

A partir dos anos de 1990, sob orientação dos organismos internacionais, foi reelaborada em todo o continente latino-americano a política de educação escolar para as minorias étnicas, levando-se em conta a interculturalidade e o bilinguismo, visando a uma melhor e mais adequada educação escolar indígena. (FAUSTINO, 2006).
No Brasil, esse processo teve início com o Decreto $n^{\circ}$. 26/1991, que determinou competir ao MEC - Ministério da Educação - coordenar as ações referentes a essa modalidade de ensino, resultando, assim, na formulação das Diretrizes para a Política Nacional de Educação Escolar Indígena, em 1992. A partir desse momento, a política se consolidou com a elaboração de inúmeros documentos, divulgação de textos acadêmicos, programas de formação de professores que atuam nas escolas indígenas, premiações a projetos de educação diferenciada e o estímulo à elaboração de materiais didáticos diversificados.

\section{Alfabetização, letramento e bilinguismo en- tre os Kaingang no Paraná}

Historicamente os Kaingang resistiram ao bilinguismo de ponte (FAUSTINO, 2006); pouquíssimos aprenderam a ler e a escrever em sua língua materna e ainda não incorporam a escrita em suas tradições. Nas Terras Indígenas Faxinal e Ivaí (Paraná), entre uma população de cerca de 2.000 pessoas, menos de 15 escrevem e leem em kaingang. $A$ maioria entre os que escrevem aprendeu palavras, frases, mas não consegue elaborar ou compreender textos em kaingang.

Pelo contexto socioeconômico, no qual se envolvem em relações interculturais, aprenderam e utilizam a língua portuguesa oral. Atualmente, aceitam e defendem a escola como um importante espaço de acesso aos conhecimentos universais e à aprendizagem da língua dominante. Uma das deficiências dessa instituição, entretanto, é apontada por Baccili e Santos (2007, p. 51): "[...] a maior parte dos erros encontrados nas redações das crianças Kaingang são erros gerados pela transferência negativa da LM para a LE".

Com a consciência, inclusive, da insuficiência de dados sobre perfis educacionais e sociais dos habitantes indígenas do Paraná que contribuam para a elaboração de políticas públicas e educacionais voltadas à questão indígena, o Programa Interdisciplinar de Estudos das Populações da Universidade Estadual de Maringá, via Programa Universidade Sem Fronteiras (SETI/Governo do Paraná), desenvolveu o projeto "Diagnóstico socioeducativo da não alfabetização indígena e Formação de agentes culturais alfabetizadores nas Terras Indígenas Ivaí, Faxinal, Queimadas e Mococa no Paraná" de 2008 a 2009.

A equipe interdisciplinar de trabalho, composta por professores e acadêmicos das áreas de Educação, Linguística, Antropologia, Ciências Sociais, História e Psicologia tem ampla experiência de campo, adquirida por meio de projetos de pesquisa e intervenção social em Terras Indígenas no Paraná. Com o financiamento do governo do estado foi possível, no âmbito desse projeto, desenvolver diversas 
ações que consistem em pesquisa de campo com entrevistas individuais voltadas a cinco eixos (dados pessoais, linguísticos, socioeconômicos, educacionais e culturais), atingindo a população adulta a partir de 15 anos; aplicação de teste para avaliação do nível de alfabetização/letramento e desenvolvimento de curso de formação de agentes culturais alfabetizadores por meio de oficinas pedagógicas.

Neste trabalho, um dos elementos que nos têm chamado atenção durante as entrevistas são as razões que levaram e ainda levam os indígenas à evasão escolar. Entre os mais velhos e os mais novos, os motivos configuram-se quase os mesmos, demonstrando que a cultura, mesmo sendo dinâmica - e tendo, por isso, sofrido diversas transformações -, mantém muitas tradições Kaingang.

Entre os mais velhos, 24,59\% afirmam ter parado de estudar para se casar, e, entre os mais jovens, o índice é de $24,53 \%$. Esses dados mostram que, apesar da relação intercultural estabelecida entre os grupos e a sociedade envolvente, e mesmo com o aumento da escolaridade, o casamento, por volta dos 14 anos para as mulheres e 17 anos para os homens, leva à incorporação de responsabilidades sendo incompatíveis com a permanência na escola.

Na aplicação do teste para avaliação da alfabetização e letramento, com a população Kaingang que tem entre 15 e 35 anos, cujo conteúdo apresenta questões relativas à interpretação de textos em língua portuguesa, produção textual, habilidades matemáticas e compreensão de um texto em língua kaingang, chamam atenção diversas questões: em primeiro lugar, observamos que o interesse pela escola se manifesta mais intensamente no discurso, pois a grande maioria, mesmo com todo o trabalho de esclarecimento que é feito, se recusa a responder o teste.

Há também a dificuldade de leitura, o que demonstra e reafirma a orientação estritamente oral que predomina entre os grupos indígenas. Reconhece-se, porém que "na atualidade, não existe cultura de oralidade primária no sentido estrito, na medida em que todas as culturas conhecem a escrita e têm alguma experiência de seus efeitos". (GALVÃO; BATISTA, 2006, p. 407).

Outras questões observadas são relativas ao ritmo de leitura (que é bastante lento em contraste com a população não indígena da mesma idade/ grau de instrução); a concentração, principalmente entre os homens (que é mínima, podendo ser desviada por um jogo de futebol, visitas à cidade, ou outro elemento externo que ocorra concomitante à aplicação do teste); a recusa ao individualismo (dificilmente fazem algo sozinhos; quando há possibilidade, se juntam para responder ao teste ou solicitam ajuda aos aplicadores); dificuldade de entendimento do conteúdo escrito (só demonstram compreensão quando o mesmo é exposto oralmente). Em nossa análise, esses elementos demonstram pouca experiência em leitura.

No terceiro momento do trabalho, que se constituiu pela realização de Oficinas Pedagógicas para a formação de agentes culturais alfabetizadores com grupos de 15 a 20 alunos adultos, foi notada a preferência dos Kaingang por relatos orais, atividades que contemplem ilustrações, trabalhos conjuntos, músicas, jogos e brincadeiras. Nas Oficinas, pudemos perceber que os Kaingang, em sala de aula, mantêm uma dinâmica bastante peculiar: interagem uns com os outros predominantemente entre si por meio da língua materna. Esse elemento enseja reflexões acerca da ação de professores índios e não índios nos processos escolares.

O estímulo à participação intensificado por questionamentos, situações problema, imagens, excertos de textos que contemplavam diferentes gêneros e propostas de atividades coletivas não foram suficientes para promover o diálogo com o professor ministrante uma vez que os cursistas optam pelo silenciamento diante do professor não índio. Esse elemento foi interpretado como sendo, além de ausência de um "repertório escolar" em língua portuguesa, decorrente da falta de "poder" de tomar a palavra perante uma "autoridade de ensino". Raramente falam com os ministrantes, mesmo que esses não sejam estranhos à comunidade e as atividades sejam planejadas prevendo o diálogo e a ampla participação.

Estudos (FAUSTINO, 2006), observações e conversas com professores índios e não índios nas Terras Indígenas Ivai e Faxinal, demonstram que também as crianças Kaingang silenciam em sala de aula, mostrando dificuldades em expressar eventuais dúvidas ou incompreensões na língua portuguesa. Geralmente remetem as dúvidas aos próprios colegas, em Kaingang.

Essa não parece ser uma questão relacionada à institucionalidade, pois a dinâmica da escola na Terra Indígena é diferente da "dos brancos": os alunos têm bastante familiaridade com os professores, têm liberdade de entrar e sair na hora que desejam da sala de aula, conversam muito entre si na língua materna, brincam bastante no pátio e nas instalações da escola, se alimentam bem no horário das refeições e riem o tempo todo. A questão do silenciamento parece estar relacionada à dificuldade de transposição entre o conhecimento espontâneo com o conhecimento sistematizado e sua aquisição via escola, pois não há desenvoltura dos Kaingang nas atividades de escrita e leitura, independentemente do conteúdo que se está trabalhando. Esse elemento demonstra a emergência da escola rever seus métodos de ensino e aprendizagem. 
Se o professor que está ministrando é indígena, muitas vezes se observa, por parte dos estudantes, menor atenção às atividades solicitadas. Perguntados sobre essa questão, os professores afirmam que, por pertencerem ao próprio grupo, os alunos têm dificuldade de identificá-los como professores. Não se encontraram estudos acerca dessa questão, ou seja, qual é a implicação de ser índio e professor em grupo étnico que se organiza por facções?

São várias as questões observadas no âmbito do projeto; de forma singular, em relação a como são estabelecidas as relações dos adultos com as crianças, cabe-nos expor um pouco sobre o universo infantil da criança Kaingang.

\section{Infância e escola entre os Kaingang}

Muito se tem falado sobre sociedades indígenas, porém, uma das questões reveladas pelo projeto remete à falta de literatura concernente ao universo infantil, suas formas de socialização primária, seus conhecimentos espontâneos e às formas de aprendizagem escolar que contribuam com o desenvolvimento das funções psicológicas superiores.

A Educação está em pauta, respaldada por leis: o direito à diversidade e a uma escola bilíngue, todavia, é contemplada de modo genérico. Ensinase, mas como e a quem? Os trabalhos existentes tanto na área de Educação como da Antropologia são específicos (estudos de casos) ou demasiadamente genéricos (não dão conta da especificidade de um grupo articulada às teorias de aprendizagem e desenvolvimento). No caso dos Kaingang, somase a esse fato a ausência de pesquisas e estudos sobre língua materna e bilinguismo. Não existem dados, por exemplo, sobre o grau de bilinguismo nas diferentes Terras Indígenas no Paraná.

De forma genérica percebe-se que uma das características marcantes da população indígena é sua tradicionalidade. Nas palavras de Fernandes (1976 apud COHN, 2002), esse modelo de sociedade precede o momento presente, é estável e regulado nos modelos ancestrais, tradições socialmente reconhecidas e aceitas por todos os membros da comunidade. É marcada também por uma organização social que garante o acesso de todos às técnicas $e$ conhecimentos, permitindo então uma participação das crianças em quase todas as atividades diárias realizadas pelos adultos.

O estudo da literatura demonstra que, para os grupos indígenas, a escola não se configura como único lugar de transmissão de conhecimento. Há muita sabedoria para ser transmitida e comunicada pelos seus membros, contribuindo assim na formação da identidade de todos. (LIMA, 2007).
De forma geral, Cohn (2002), Fernandes (1975), Schaden (1976), Meliá (1979) e outros afirmam ser marcante a valorização na educação dita informal, o aprendizado que acontece diariamente, com os pais, parentes e os mais velhos da aldeia (pertencentes ao mesmo grupo familiar). Pode-se então afirmar que a aprendizagem se dá a todo o momento. As crianças estão em "todos os lugares" e há uma grande permissividade no modo como a criança circula por toda a aldeia e se relaciona com os adultos, sendo tratada com ternura e cuidado. (COHN, 2002).

Em nosso trabalho de campo nas Terras Kaingang no Paraná, pudemos notar essa "onipresença" das crianças, seja na escola, na unidade de saúde, na igreja, na recepção de visitas, nos espaços de convivência coletivos - enfim, na institucionalidade, existente no centro da aldeia.

Um fato marcante que suscitou nossa reflexão foi o óbito de uma criança de aproximadamente 7 anos, ocorrido na Terra Indígena Faxinal, por uma doença congênita. Quando trouxeram o corpo da criança para ser velado na igreja, todas as crianças da aldeia compareceram ao velório. O caixão foi posto no centro da igreja, com vários bancos ao redor, onde permaneceram as índias mais idosas. As crianças participaram do velório, ou sentados nos bancos, ou em pé ao lado do caixão da criança, ou mesmo correndo ao redor.

Às vezes, confundido com permissividade, podemos, em contrapartida, salientar um respeito especial pela criança, pelo seu entendimento de mundo; elas parecem ser as únicas na aldeia que têm o direito de estar em todo lugar, participar de todos os acontecimentos sociais. De acordo com Lima (2007), entre os membros de uma comunidade indígena não há um grupo responsável pela transmissão dos saberes, assim como não há apenas um membro agente da educação indígena. Tem-se o princípio de que "todos ensinam a todos", e não há uma hora apropriada para aprender; há um respeito pelo tempo certo de cada um, por isso não se observa muita "ansiedade" ou preocupação exagerada dos adultos em ensinar às crianças pelas palavras. De forma geral, elas parecem aprender mais pela observação, imitação.

Tal fator se expressa na produção do artesanato, quando as crianças participam ajudando, fazendo pequenos cestos, vendendo, carregando-os para as mães, avós e tias.

$\mathrm{Na}$ vida diária, todos ensinam. Essa questão se evidencia na fala de um entrevistado, quando ele diz que "ele era professor, pois ensinou o que sabe aos filhos, os ensinava na roça. A mulher também é professora, pois ensina as coisas de casa aos piá [...]" (Sr. A.; T. I. Faxinal, informação verbal). 
Essa afirmação demonstra o valor que é atribuído ao aprendizado não escolar, por meio das relações de trabalho; em todas as atividades do dia a dia as crianças são chamadas a dar recados, levar mantimentos, buscar chaves, fazer entregas, cuidar dos menores, etc. Em nenhuma ocasião observamos a recusa da criança em atender a esses pedidos dos mais velhos.

Nas palavras de Lima (2007) e Schaden (1976), as crianças indígenas aprendem "brincando". Na brincadeira, pela imitação, a criança experiencia e constrói referências que Ihe dão a percepção de dimensões espaciais e temporais, familiares, bem como o conhecimento do que é de domínio individual e de domínio coletivo, configurando-se em um aprendizado que acompanhará o indivíduo ao longo de sua vida.

Essa educação tradicional é responsabilidade da comunidade e disseminada através da oralidade, de modo coletivo. A educação está pautada no fazer diário, e há aplicabilidade nessa aquisição de conhecimento, como o trabalho na roça, o trabalho em casa, o trabalho com o artesanato, o cuidar dos irmãos mais novos, ou o respeitar uma orientação dada pelos adultos. Dessa forma, em uma cultura tradicionalmente oral e baseada no fazer diário, a linguagem escrita se torna insípida, e tem pouca funcionalidade. Somado a isso, temos o fato de que a inserção da educação formal foi, em princípio, imposta pela sociedade dominante como meio de pacificação ou catequização dos povos indígenas.

Embora hoje seja evidente que aprender a língua portuguesa é um instrumento que os auxilia na compreensão e nas relações com a sociedade envolvente, como o domínio do conhecimento científico, da compreensão das leis etc., aprender o português oral, para os Kaingang é fator importante para a autonomia fora da aldeia. Nesse sentido, não se dá maior importância à língua kaingang escrita.

Foi possível a observação desse fenômeno em nossas viagens a campo, nas quais constatamos que a maior parte da evasão escolar ocorre por volta da $4^{\mathrm{a}}$ ou $5^{\mathrm{a}}$ série do Ensino Fundamental. Os fatores que influenciam nessa evasão escolar precisam ser melhor estudados, porém remetem a questões culturais, linguísticas e políticas, uma vez que a "aceitação" da instituição escolar ainda é recente e ainda vista apenas como um instrumento de mediação entre a cultura indígena e a sociedade dominante, ou como uma forma de conseguir um emprego, uma renda a curto prazo.

Ainda não há entre os Kaingang no Paraná a compreensão plena sobre o papel da aprendizagem escolar, da aquisição do conhecimento sistematizado como uma forma de desenvolver funções intelectuais superiores (memória, percepção, sentimentos, capacidade de análise e síntese), pois essas, entre o grupo, são desenvolvidas por meio de outras estratégias.

$\mathrm{Na}$ pesquisa realizada para averiguar o nível de alfabetização e letramento entre jovens e adultos, o fator casamento foi o elemento mais apontado na desistência escolar, sendo seguido pela necessidade de trabalhar em sua própria roça. Na cultura Kaingang, a criança se torna adulta muito cedo, se considerarmos os padrões da sociedade envolvente. Por volta dos 12 anos, a criança já se encaminha para a vida adulta, com todas as responsabilidades dessa. No caso das meninas, sua entrada na vida adulta se dá com a menarca, período em que já podem se casar ou ter uma vida sexual ativa. Com essa idade, também os meninos já podem ter sua própria roça e ir tomando as decisões sobre sua própria vida.

Diferentemente da cultura ocidental que tenta conciliar o estudo/trabalho, ou o estudo/família, na cultura indígena parece não haver essa dinâmica. Porém, acreditamos que essa questão não é simples como parece: sendo a escola instalada na própria aldeia, o casamento e o trabalho não seriam propriamente impedimento relevante aos estudos. Há outras questões relacionadas à cosmovisão do grupo e o lugar ocupado pela aprendizagem escolar, que só serão evidenciadas/interpretadas com muitos estudos e variadas fontes.

\section{Considerações Finais}

De forma geral, os indígenas não podem mais reproduzir suas formas de vida tradicionais apoiados apenas em seus conhecimentos milenares, tendo que se adaptar à cultura dominante, ressignificando sua cultural tradicional. $E$ isso é o que eles têm feito e o que lhes garantiu a sobrevivência nesses séculos de contato com a sociedade envolvente.

Porém, essa adaptação é feita de escolhas e nem sempre o discurso reproduz o que de fato ocorre na organização sociocultural do grupo. Alguns aspectos da cultura tradicional são muito bem guardados e se mostram resistentes às mudanças. Entre a população Kaingang no Paraná, ressalta-se a importância da instituição escolar, porém a pesquisa evidencia que não houve a internalização desse pensamento e a escola é elemento secundário entre o grupo. A função da escrita, a utilização da língua materna em textos escritos, a criação de uma literatura indígena autêntica e o papel da escola como transmissora de conhecimentos ainda estão por se solidificar entre os grupos.

Somada a isso, a ausência de materiais diversificados escritos em língua Kaingang torna difícil a alfabetização das crianças indígenas em sua língua materna, como orienta a nova política de educação 
Aprendizagem escolar entre indígenas Kaingang no Paraná: questões sobre língua...

escolar indígena. Pela pouca formação acadêmica e devido à centralização na oralidade, os professores têm dificuldades de escrever textos em Kaingang, não promovendo o caráter identitário da língua escrita. Esses elementos pouco favorecem o letramento entre o grupo. Nas casas, não são encontrados materiais de leitura (revistas, jornais, livros, etc.).

É necessário considerar que a educação escolar indígena merece um aprofundamento por parte das pesquisas universitárias e intervenções pedagógicas mais apropriadas à diversidade, pois estamos diante de uma cultura com dinâmicas diferenciadas e que está inserida no contexto do Estado brasileiro. Cabe, por isso, respeitar, reconhecer, trabalhar com as particularidades do grupo e construir, de acordo com as reivindicações, um ensino de qualidade, que possa formar uma geração de indígenas capacitados a exigirem os seus direitos e a praticarem sua autonomia, a participarem com consciência do entorno e a liderarem seu povo conforme suas identidades coletivas.

Planejado e executado em um período de mudanças e alterações na política educacional e legislação dirigida aos povos indígenas, o projeto oportunizou o conhecimento sobre aspectos da escolarização Kaingang possibilitando que se discutissem tanto a permanência de um bilinguismo - que pouco contribui para a aprendizagem e uso da língua materna escrita em contextos sociais mais amplos -, quanto a necessidade de maiores pesquisas na área da educação escolar indígena - abrangendo a Linguística, a Antropologia, a História e a Pedagogia -, bem como uma reflexão sobre a importância da escrita e da leitura, no contexto atual de busca pela autonomia indígena.

\section{Referências}

BACCILI, V. C. L.; SANTOS, L. C. Reflexões sobre a influência da língua materna Kaingang no aprendizado do português como segunda língua. Entretextos, Londrina, v. 7, p. 40-53, 2007.

BARROS, M. C. D. M. Linguística missionária: Summer Institute of Linguistics. 1993. $736 \mathrm{f}$. Tese (Doutorado em Ciências Sociais) - Instituto de Filosofia e Ciências Sociais, Universidade Estadual de Campinas, Campinas, 1993.

Educação bilíngüe, lingüística e missionários. Em Aberto, Brasília, v. 14, n. 63, p. 18-37, jul./set. 1994.

A missão Summer Institute of Linguistics e o indigenismo latino-americano: história de uma aliança (décadas de 1930 a 1970). Revista de Antropologia, São Paulo, v. 47, n. 1, p. 45-85, jan./jun. 2004.

COHN, C. A criança, o aprendizado e a socialização na antropologia. In: SILVA, A. L. da.; NUNES, A.; MACEDO, A. V. L. S. da (Orgs.). Crianças indígenas: ensaios antropológicos. São Paulo: Global, 2002. p. 213-235.
D’ANGELIS, W. A língua kaingang. Disponível em: <http:// www.portalkaingang.org/lgua_kaingang.pdf>. Acesso em: 11 out. 2007.

FAUSTINO, R. C. Política educacional nos anos de 1990: o multiculturalismo e a interculturalidade na educação escolar indígena. 2006. 330 f. Tese (Doutorado em Educação) - Programa de Pós-Graduação em Educação, Universidade Federal de Santa Catarina, Florianópolis, 2006.

FERNANDES, F. Notas sobre a educação na sociedade Tupinambá. In: Investigação etnológica no Brasil e outros ensaios. Petrópolis: Vozes, 1975. p. 3383.

GABAS JR., N. Lingüística Histórica. In: MUSSALIM, F.; BENTES, A. C. (Orgs.). Introdução à lingüística: domínios e fronteiras. 6. ed. São Paulo: Cortez, 2006. v. 1. p. 77-103.

GALVÃO, A. M. de. O.; BATISTA, A. A. G. Oralidade e escrita: uma revisão. Cadernos de Pesquisa, São Paulo, v. 36, n. 128, p. 403-432, maio/ago. 2006.

GARCIA, E. F. O projeto pombalino de imposição da língua portuguesa aos índios e a sua aplicação na América Meridional. Revista Tempo, Niterói, v. 12, n. 23, p. 23-38, jul. 2007.

LEITE, Y. O Summer Institute of Linguistics: estratégias de ação no Brasil. Religião e Sociedade, Rio de Janeiro, n. 7, p. 60-64, 1981.

LIMA, E. G. de; NASCIMENTO, A. C. O valor da comunidade indígena na construção da identidade da criança terena. In: Congresso de leitura do Brasil, 16., 2007, Campinas. Anais... Campinas: Unicamp, 2007. Disponível em: <http://www.alb.com.br/anais16/>. Acesso em: 09 jul. 2008.

MELIÁ, B. Educação indígena e alfabetização. São Paulo: Edições Loyola, 1979. (Coleção Missão Aberta).

MOTA, L. T. O Instituto Histórico e Geográfico Brasileiro e as propostas de integração das comunidades indígenas no Estado Nacional. Diálogos, Maringá, n. 2, p. 149-175, 1998.

SCHADEN, E. Educação indígena. Problemas brasileiros, São Paulo, v. XIV, n. 152, p. 23-32, abr. 1976.

SILVA, C. L. Sobreviventes do extermínio: uma etnografia das narrativas e lembranças da sociedade Xetá. 1998. 290 f. Dissertação (Mestrado em Antropologia Social) - Programa de Pós-Graduação em Antropologia Social, Universidade Federal de Santa Catarina. Florianópolis, 1998.

SILVA, C. R. da. História crítica da construção da escrita do Kaingang.1996. 109 f. Dissertação (Mestrado em Letras) - Programa de Pós-Graduação em Letras, Universidade Estadual de Londrina, Paraná, 1996.

VIGOTSKY, L. S. Pensamento e Linguagem. São Paulo: Martins Fontes, 1987.

Recebido em 13/03/2010

Aceito em 23/07/2010 